\title{
An Architectural Perspective on Structured Sacred Space-Recent Evidence from Iron Age Ireland
}

Frank Prendergast

Technological University Dublin, frank.prendergast@tudublin.ie

Follow this and additional works at: https://arrow.tudublin.ie/arastbk

Part of the Archaeological Anthropology Commons, Other Architecture Commons, Other Engineering Commons, and the Social and Cultural Anthropology Commons

\section{Recommended Citation}

Prendergast, Frank. 2015. "An Architectural Perspective on Structured Sacred Space-Recent Evidence from Iron Age Ireland." In Skyscapes in Archaeology: The Role and Importance of the Sky, edited by Fabio Silva and Nicholas Campion, 87-105. Oxford \& Philadelphia: Oxbow Books.

This Book Chapter is brought to you for free and open access by the Archaeoastronomy Research at ARROW@TU Dublin. It has been accepted for inclusion in Book/Book Chapter by an authorized administrator of ARROW@TU Dublin. For more information, please contact arrow.admin@tudublin.ie, aisling.coyne@tudublin.ie,gerard.connolly@tudublin.ie.

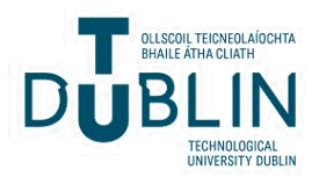


This pdf of your paper in Skyscapes belongs to the publishers Oxbow Books and it is their copyright.

As author you are licenced to make up to 50 offprints from it, but beyond that you may not publish it on the World Wide Web until three years from publication (March 2018), unless the site is a limited access intranet (password protected). If you have queries about this please contact the editorial department at Oxbow Books (editorial@ oxbowbooks.com). 


\title{
An offprint from SKYSCAPES \\ The Role and Importance of the Sky in Archaeology
}

\author{
edited by \\ Fabio Silva and Nicholas Campion
}

Paperback Edition: ISBN 978-1-78297-840-4

Digital Edition: ISBN 978-1-78297-841-1

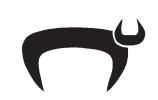

(C) Oxbow Books 2015

Oxford \& Philadelphia 
Published in the United Kingdom in 2015 by

OXBOW BOOKS

10 Hythe Bridge Street, Oxford OX1 2EW

and in the United States by

OXBOW BOOKS

908 Darby Road, Havertown, PA 19083

(C) Oxbow Books and the individual contributors 2015

Paperback Edition: ISBN 978-1-78297-840-4

Digital Edition: ISBN 978-1-78297-841-1

A CIP record for this book is available from the British Library

Library of Congress Cataloging-in-Publication Data

Skyscapes : the role and importance of the sky in archaeology / edited by Fabio Silva and Nicholas

Campion.

pages $\mathrm{cm}$

Includes bibliographical references.

ISBN 978-1-78297-840-4 (paperback) -- ISBN 978-1-78297-841-1 (digital) 1. Archaeoastronomy. 2.

Landscape archaeology. 3. Sky--Social aspects--History. 4. Cosmology--History. 5. Astrology--History.

6. Sacred space--History. 7. Prehistoric peoples. 8. Social archaeology. I. Silva, Fabio (Fabio P.) II.

Campion, Nicholas.

GN799.A8S54 2015

$523.1--d c 23$

2015002812

All rights reserved. No part of this book may be reproduced or transmitted in any form or by any means, electronic or mechanical including photocopying, recording or by any information storage and retrieval system, without permission from the publisher in writing.

Printed in the United Kingdom by Short Run Press, Exeter

For a complete list of Oxbow titles, please contact:

\section{UNITED KINGDOM}

Oxbow Books

Telephone (01865) 241249, Fax (01865) 794449

Email: oxbow@oxbowbooks.com

www.oxbowbooks.com

Oxbow Books is part of the Casemate Group

\section{UNITED STATES OF AMERICA}

Oxbow Books

Telephone (800) 791-9354, Fax (610) 853-9146

Email: queries@casemateacademic.com

www.casemateacademic.com/oxbow

Front cover: Vincent Van Gogh's Starry Night, 1889. Museum of Modern Art, New York, USA/ Bridgeman Images

Back cover: The huaca of Moray, Peru (photo by Tore Lomsdalen). 


\section{CONTENTS}

List of Contributors $\quad$ vii

Preface: Meaning and Intent in Ancient Skyscapes - An Andean Perspective ix

J. McKim Malville

1. The Role and Importance of the Sky in Archaeology: An Introduction 1 Fabio Silva

2. Skyscapes: Locating Archaeoastronomy within Academia 8 Nicholas Campion

3. An Examination of the Divide Between Archaeoastronomy and Archaeology 20 Liz Henty

4. Skyscapes: Present and Past - From Sustainability to Interpreting Ancient Remains

Daniel Brown

5. $30 \mathrm{~b}$ - the West Kennet Avenue Stone that Never Was: Interpretation by Multidisciplinary Triangulation and Emergence through Four Field Anthropology

Lionel Sims

6. Can Archaeoastronomy Inform Archaeology on the Building Chronology of the Mnajdra Neolithic Temple in Malta?

Tore Lomsdalen

7. Star Phases: the Naked-eye Astronomy of the Old Kingdom Pyramid Texts Bernadette Brady

8. An Architectural Perspective on Structured Sacred Space - Recent Evidence from Iron Age Ireland Frank Prendergast 
9. The Circumpolar Skyscape of a Pembrokeshire Dolmen 106 Olwyn Pritchard

10. The View from Within: a 'Time-Space-Action' Approach to Megalithism in Central Portugal

Fabio Silva

11. Afterword: Dances Beneath a Diamond Sky

Timothy Darvill 


\title{
An Architectural Perspective on Structured Sacred Space - Recent Evidence from Iron Age Ireland
}

\author{
Frank Prendergast
}

'A society which does not believe in its survival is incapable of the symbolic representation of its aim, and therefore incapable of building'

(Krier 1992)

Archaeological visibility of Iron Age society in Ireland has been described as enigmatic owing to the relative paucity of the material culture and settlement record for the period (Raftery 1994, 112). Becker $(2009,354)$ regards this period of Irish prehistory as extending from $700 \mathrm{BC}$ to $400 \mathrm{BC}$ (Early Iron Age), $400 \mathrm{BC}$ to $1 \mathrm{AD}$ (Developed Iron Age), and AD 1 to $\mathrm{AD} 400$ (Late Iron Age). In contrast to the abundant record of sites and monuments available for the Neolithic and the Bronze Age periods, this comparative invisibility continues, notwithstanding the rapid growth in the rate of site discovery resulting from recent infrastructural development projects - especially the national roads programme (e.g. Mc Laughlin and Conran 2008; Taylor 2008). Moreover, an analysis of the almost 1,000 sites currently hosted on the web-based NRA Archaeological Database (http://www.nra.ie/ Archaeology/) indicates that a mere $8 \%$ of those have yielded Iron Age dates (Mc Carthy 2010).

As described by O'Connell $(2013,61)$, the discovery in 2007 of the likely Iron Age pagan temple site at Lismullin, Co, Meath (hereinafter Lismullin 1), has yielded an 'extraordinary' and rare example of a ceremonial complex of this type. Radiocarbon dating by Marshall et al. $(2013,141-45)$ indicates that construction of the monument began in c. 455-400 BC (68\% probability) and for it to have gone out of use in c. 370-330 BC (38\% probability). These data thus chronologically place it at the transition of the Early and Developed Iron Ages, and suggest longevity of just a few generations for the site.

Convincing evidence for the claimed role of Lismullin 1 as a ceremonial site is contained in the meticulous archaeological excavation record (see O' Connell 2013) and in the outcomes of a range of commissioned specialist reports ( $\mathrm{ibid}$.), including geospatial analysis. From those, the absence of any evidence for human burial or habitation in the material record is interpreted as indicating a probable restricted ritual use for the complex. Significantly, the analysis of soil chemistry for variations arising from natural and cultural processes demonstrates that the buried soils are derived from local parent material and do not contain significant cultural elements that may reflect site function (Lancaster 2008). Lancaster further concludes 'It is highly unlikely that the chemical analysis of the other samples taken for this 
purpose will produce data that will provide significant evidence of past cultural activities' and that such a 'chemically clean signature' is highly consistent with the reserved/controlled use of this space, unlike most archaeological sites. This makes the site anomalous when usage is assessed by conventional archaeological criteria.

Collectively, these findings support the thesis that the complex was built as a focal structure to facilitate public gathering and ceremonies, and give significant weight for its designation as a temple by O' Connell.

\section{Lismullin 1 - A Ritual Pagan Temple?}

With relevance to this discussion, and because of the uniqueness of the typology of the structure, a summary description of Lismullin 1 is warranted. Firstly, two attributes can readily explain its exclusiveness in design terms. The architectural style replicates a method of construction more typical of the Late Neolithic (c. 2850-2450 BC) than of the Iron Age (e.g. Gibson 2005). Secondly, the landscape setting differs profoundly from the prominent hilltop setting encountered at Irish Iron Age royal sites with which Lismullin 1 can be compared. Moreover, the complex is situated in a natural saucer-shaped depression adjacent to a river (Fig. 8.1). The large diameter of the outer enclosure, and the minimal thickness of

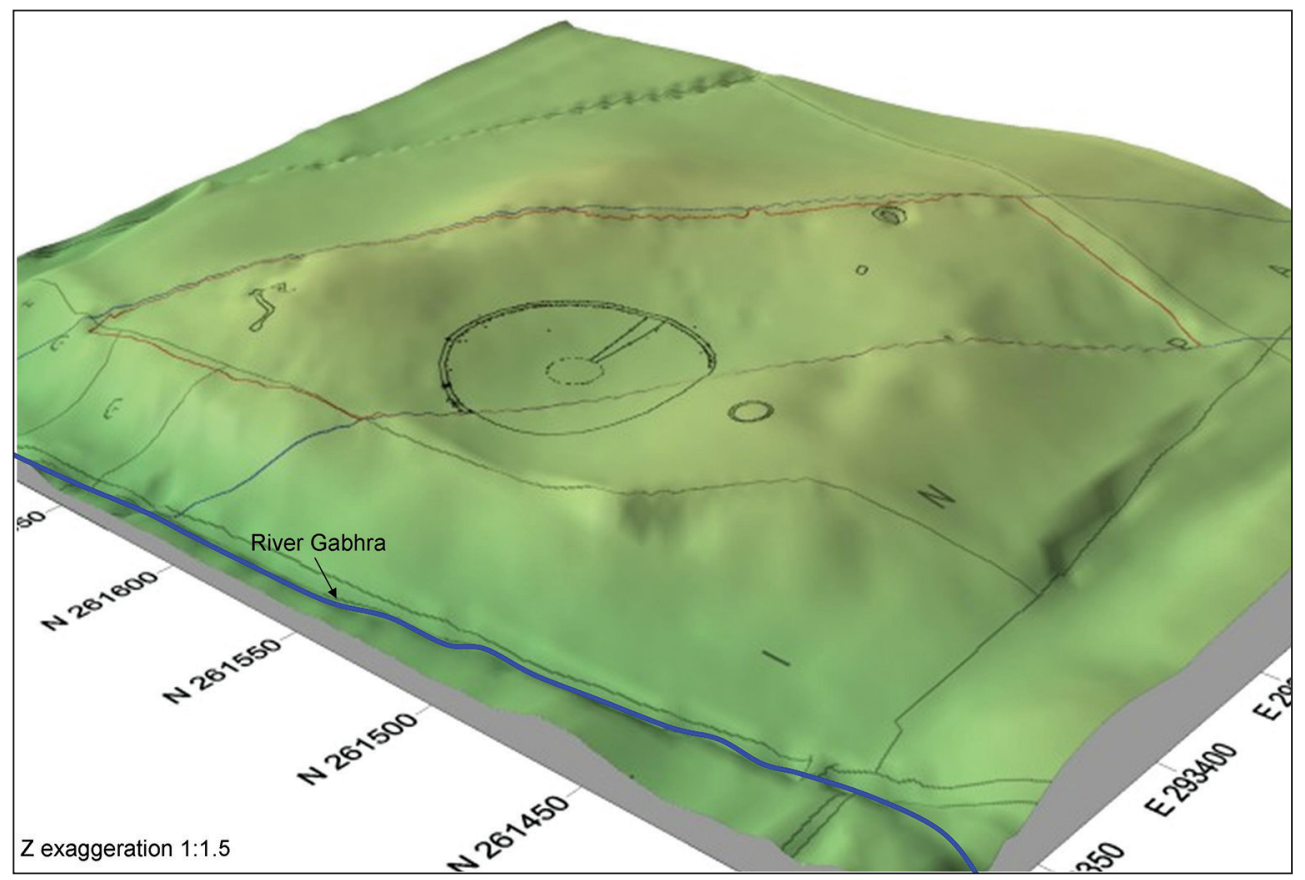

Fig. 8.1: Landscape setting of Lismullin 1. The digital elevation model is courtesy of Archer Heritage Planning. The location coordinates are expressed in metres in the Irish Grid reference system. The vertical relief is exaggerated at 1:1.5. 
the timber posts inferred from the size of the recovered post-holes, suggest that the structure would have been incapable of supporting a roof. This potentially integrates the sky into the phenomenology and cosmology of the site, and how it may have been used.

Such a setting, characterised as it is by topographical discreteness, centrality within a natural surrounding ridge, openness to the sky, and proximity to flowing water, collectively contribute to its 'genius loci' (spirit of the place) - a qualitative term used by Norberg-Schulz (1980). These ideas are explored later in the paper.

\section{Summary spatial description}

The discovery of the sub-surface traces of c. 590 upright wooden posts in 2007 was as a direct result of mandatory archaeological and environmental monitoring undertaken in advance of construction of the M3 motorway. When fully recorded, the patterns that emerged from the recovered post-holes delineated the following circular and linear elements (Fig. 8.2):

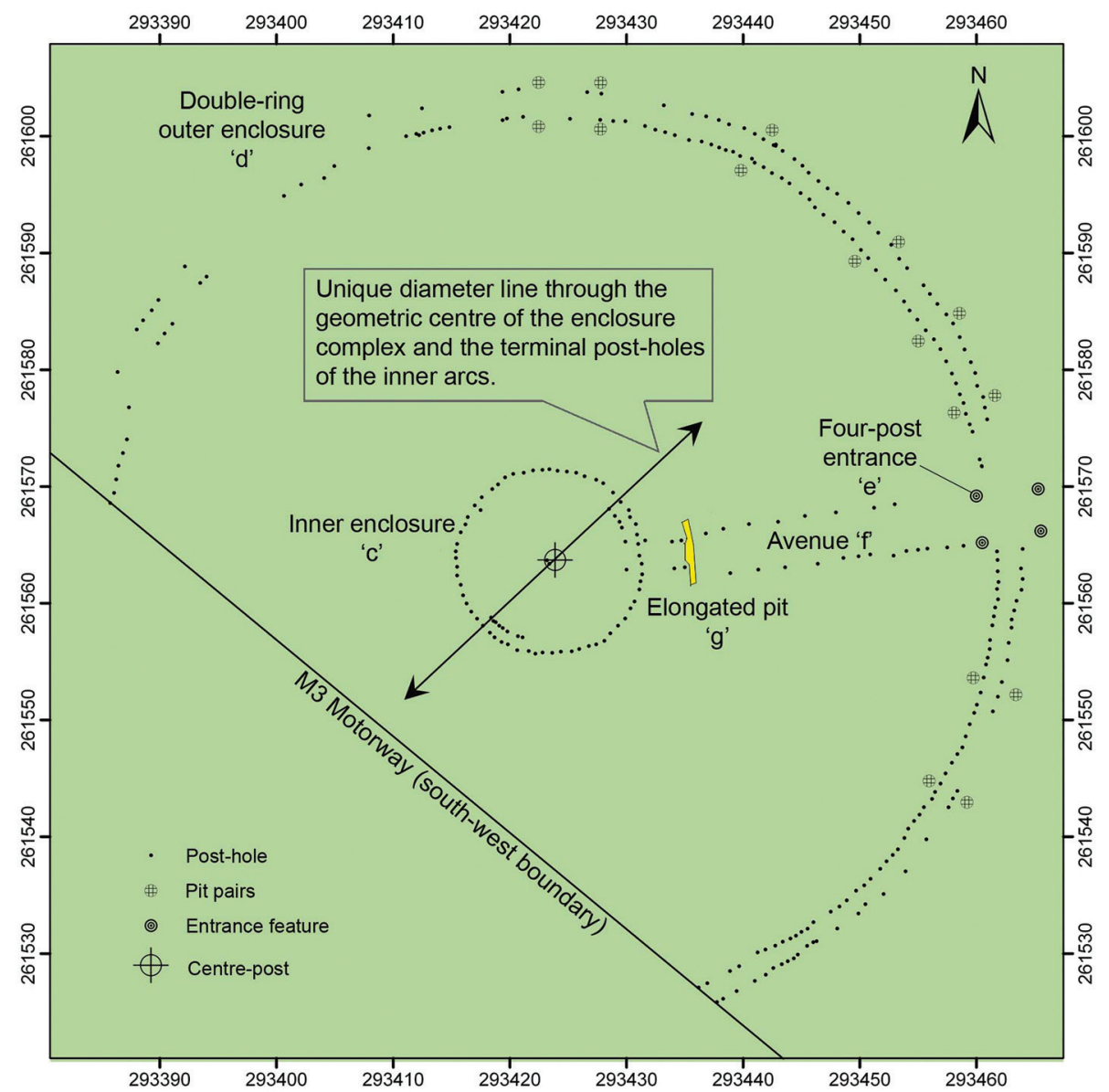

Fig. 8.2: Site plan of Lismullin 1. The grid coordinates are in metres on the Irish Grid reference system. 
- $\quad$ Inner enclosure ring c (radius $7.97 \pm 0.11 \mathrm{~m}$ );

- $\quad$ Outer enclosure double ring d (radii $40.25 \pm 0.28 \mathrm{~m}, 38.30 \pm 0.28 \mathrm{~m}$ );

- Two short arcs of post-holes inset by c. $1.0 \mathrm{~m}$ from the inner enclosure;

- Avenue f facing east-northeast (width $3.96 \pm 0.13 \mathrm{~m}$, outward azimuth/declination $83^{\circ} .8 /+5^{\circ} .0$, reverse azimuth/declination $263^{\circ} .8 /-3^{\circ} .2$ );

- $\quad$ Entrance feature e articulated by four larger diameter/deeper post-holes;

- Elongated pit g set transversely to the avenue at its western terminal and offset by $4.05 \pm 0.20 \mathrm{~m}$ from $\mathrm{c}$.

Quantities of charcoal, burnt animal bone and burnt hazelnut shells were recovered in the elongated pit - indicative of the use of fire and probable ceremonial/ritual deposition. Environmental assessment has indicated the presence of significant quantities of Corylus avellana (hazel) which could reflect the use of wattling being used as a weave between the posts made of Fraxinus excelsior (ash). The discovery of Maloideae (rose-type wood) further suggests that flower or fruit-bearing branches may have been used to decorate the structure, possibly for their aesthetic effect (see O'Connell 2013, 174).

The prevalence of high-status monuments in Ireland during the Iron Age, and the surviving corpus of prestige high-quality metalwork in the form of weaponry and horse-bits, and La Tène-style art (e.g. Raftery 1994), indicate an established sophisticated culture at that time. Although evident to the excavation archaeologists, the obvious formality embedded in the form of Lismullin 1 was consistent with the idea that the complex embodied concepts of elegant planning, proportionality and regularity. Such perceptions are consistent with its probable usage as a religious temple and for the segregation and ordered coordination of a large group of users. While such conjecture has its place in any narrative, the availability of high-quality spatial data has allowed its numerical analysis to test these claims (Prendergast 2012, 2013). The outcomes are summarised here to underpin later discussion.

\section{Geospatial analysis}

Post-holes and the outline of the elongated pit were recorded with centimetre accuracy. Thus, for the purpose of investigation of the retrospective construction methods and intentions of the builders of Lismullin 1, the extant archaeological record can be assumed to be effectively error free. Even from a mere visual inspection of the post-hole data, it is evident that the complex consists of nothing more than circles and straight lines. Such a structure could have thus been simply constructed with the rope and peg method - the likely technology of the time (Atkinson 1961, 295; 1974, 128).

The geospatial analysis investigated the following three properties:

- $\quad$ Structure morphology and concentricity;

- $\quad$ Structure metrology and proportionality;

- Archaeoastronomical properties.

The results indicate that:

- The three circles of the inner and outer enclosures were set-out from a common centre (numerically derived using the method of least squares). The residual errors between each post-hole of circle a and both circles of $d$, and their respective best-fit circle, support this hypothesis with a probability of $0.03,0.05$ and 0.06 respectively, at $95 \%$ confidence level. Significantly, an excavated post-hole found within $0.50 \mathrm{~m}$ of the 
Table 8.1: Dimensions of the enclosure's elements.

\begin{tabular}{|c|c|c|c|c|}
\hline Element & $\begin{array}{c}\text { Mean } \\
\text { length m }\end{array}$ & $\begin{array}{r}\text { Length sca } \\
\text { means cc }\end{array}$ & $\begin{array}{l}\text { U for } \\
\text { ison }\end{array}$ & Remarks \\
\hline Radius of the inner enclosure $U$ & 7.97 & - & - & Unit of measurement $U$ \\
\hline Width of avenue and entrance & 3.96 & 0.50 & $X^{1 / 2}$ & Half $U$ \\
\hline Outer enclosure radius & 40.25 & 5.05 & X 5 & Five U \\
\hline $\begin{array}{l}\text { Gaps between rings in outer } \\
\text { enclosure }\end{array}$ & 1.95 & 0.25 & $X 1 / 4$ & Quarter U \\
\hline $\begin{array}{l}\text { Gap between internal arcs and } \\
\text { inner enclosure }\end{array}$ & 1.02 & 0.13 & $\mathrm{X}^{1 / 8}$ & Eighth of $U$ \\
\hline $\begin{array}{l}\text { Pitch between posts in the outer } \\
\text { enclosure }\end{array}$ & 1.04 & 0.13 & $X^{1 / 8}$ & Eight of $U$ \\
\hline $\begin{array}{l}\text { Gap between inner enclosure } \\
\text { and west side of elongated pit }\end{array}$ & 4.05 & 0.51 & $X^{1 / 2}$ & Half of $U$ \\
\hline
\end{tabular}

derived geometric centre of $\mathrm{c}$ is now interpreted by archaeologists (probability 0.3 , at $95 \%$ confidence level) as the point that could have marked the ritual centre of the enclosure. There is additional numerical evidence from statistical analysis of pitch values that the post-holes located in the two rings of the outer enclosure were set-out in a radial manner and as a single act of construction (Prendergast 2012).

- The avenue between the elongated pit and the entrance was set-out as two parallel lines - most likely using the simple technique of offsetting the opposite side with a constant length of rope. Linear regression analysis of each avenue side for conformity to a straight line yielded correlation coefficients $\mathrm{R}^{2}$ of 0.99 and 0.98 , and parallelism within $\pm 0.13 \mathrm{~m}$ (probability 0.05 , at $95 \%$ confidence level) to support these claims.

- The analysis of variance (ANOVA) method provides convincing evidence that the different elements of the enclosure were constructed in a proportional manner (Table $8.1)$.

In the statistical comparison between the lengths of the different elements of the post enclosure shown in Table 8.1, the null hypothesis being tested is that at least two of the mean lengths are the same i.e. $\mathrm{m}_{1}=\mathrm{m}_{2}=\mathrm{m}_{3}=\ldots \ldots \mathrm{m}_{\mathrm{k}}$. The results indicate that the eight means are the same and the null hypothesis $\mathrm{H}_{0}$ is not rejected $\left(p=0.674, \mathrm{~F}_{\text {crit }}=2.03, \mathrm{n}=\right.$ $368,95 \%$ confidence level). Adopting the width of the avenue as an alternative standard unit of measurement for this test made no significant difference to the outcome. The radius of the inner enclosure is thus argued as the most likely and pragmatic standard unit of measurement used to build the complex. By simply and successively halving this length (by folding of the rope), the width of the avenue, the gap between the inner enclosure and the pit, and the gap between the rings of the outer enclosure could have been dimensionally controlled to a high level of exactness. The outermost ring could also have been set-out using a radius length equal to five times that of the inner enclosure. Moreover, the width of the gap between the outer rings is one quarter of the radius of the inner enclosure. 
The scale of Lismullin1 was most probably dictated by the diameter of the natural circular ridge within which it is centrally positioned (see Fig. 8.1). This hypothesis argues that the standard unit of measurement was merely a locally conceived design solution that optimised the fit of the complex to the available circular space enclosed by the surrounding ridge. By placing the elongated pit transversely to the axis of the avenue, it would likely have acted as a barrier to any procession i.e. of people moving from the entrance towards the presumed sacred inner enclosure at the centre. The pit is therefore interpreted as a threshold and, arguably, this may have been the most significant element of the whole complex.

- Archaeoastronomical assessment of the complex has focussed on the well defined linearity of the avenue and its axis - the invisible directional line that conceptually unites the observer, the avenue and the sky. This direction is given pre-eminence in that the avenue would have functioned as a means of formal entry and exit, as well as for procession. The avenue faces east-northeast. The azimuth and astronomical declination of its axis yielded no significant horizon-based astronomically significant events in terms of solar extremes or lunar maxima. Using planetarium software to correct the viewed night sky for the effect of precession in c. $400 \mathrm{BC}$, it is argued that the avenue may have been intentionally orientated so as to align upon the autumnal appearance of the Pleiades (Fig. 8.3). Such a time of year may have been significant insofar as the passage of this distinctive cluster of stars above the avenue when its altitude was $c .12^{\circ}$ would have been a clearly visible and recurring seasonal phenomenon in the night-time sky - perhaps coinciding with the ending of the harvest and before the onset of winter. By about the end of October, this alignment would occur in daylight, thus ending the spectacle until its predictable return the following year. Additionally, the appearance of the rising sun or, perhaps, a rising autumnal full moon on the declination of the avenue may have acted as a temporal trigger for the commencement of any hypothetical nocturnal rituals (the azimuth and horizon altitude of the avenue's axis at Lismullin 1 indicate solar and lunar declinations of $c .5^{\circ} .0$ and $5^{\circ} .8$ respectively). Although occurring north of the avenue's orientation, the heliacal rising of the Pleiades in late April may also have had agricultural or ritual significance in springtime. Collectively, these phenomena strengthen the argument for the seasonal use of Lismullin1 around sowing and/or harvest periods.

This interpretation is just one of many other plausible alternatives, including the hypothesis that orientation could have been random. Critically, because of the uniqueness of the site, statistical backing cannot be offered. However, alignment on the risen Pleiades (after its apparent brightness has overcome the light-absorbing effect of the atmosphere close to the horizon, especially in northern latitudes) is consistent with the generally held view that this visually distinctive cluster was important to indigenous and prehistoric societies. It has been linked to the regulation of calendars and planting, harvesting and festival cycles (e.g. Aldhouse-Green 2010, 110; Boutsikas and Ruggles 2011; Ceci 1978; Cunliffe 2002; Kirch 2004; Oldfather 1935, 1939; Ruggles 2005).

The analysis of post-hole locations has quantified the evident formality in the design of Lismullin 1. When contextualised with the findings of the comprehensive archaeological excavation, and the related findings of the specialist reports, evidence of a relatively invisible period of Irish prehistory has improved. However, such quantitative methods do not necessarily fully explore, nor penetrate, the underlying motivations and decision making rationale behind the construction of such an enclosure. The following qualitative approaches, 
while subjective and speculative, have the potential to broaden the narrative for enquiry into design intent and possible relevance to local ritual and religious practices. As Oscar Wilde stated $(1891,181)$ 'An idea that is not dangerous is unworthy of being called an idea at all'.

Here, ritual is taken to mean practices associated with supernatural or religious experiences or beliefs, and as a result of material culture being deliberately situated for such purposes (Darvill 2002, 361). Darvill further adds 'in non-westernised societies there is no formal boundary between what is ritual and secular, between the sacred and the profane'.

\section{Social Network Analysis and Narrative Structuring}

If Lismullin 1 was used as a pagan temple, then a more developed terminology is required to explore the role and meaning of this site in the Iron Age. Qualitative terms already used include genius loci, sacred place, focal, enclosure, circle, axis, procession and threshold. Each is fundamental in the language and discourses of design philosophy (e.g. Heidegger and Hofstadter 1971), and architectural design theorists (e.g. Barrie 2012; Holl et al. 1994; Krier 1992; Norberg-Schulz 1980, 1985, 2000; Rykwert 1988). Where borrowed from those disciplines, a more complete typology of relevant concepts for narrative purposes is given in Table 8.2 to help address the more fundamental questions raised by all prehistoric architectural constructs and archetypes, Lismullin 1 included.

The data in Table 8.2 are typified here as ideational i.e. characterised by their intended meaning(s) and motivation(s) in the mind of the designer as distinct from attribute or relational type data which are measureable and observable. However, ideational data are subject to individual judgement and interpretation and this can result in analytical outcomes that are neither mutually exclusive nor unique. While such boundary problems and dangers of misinterpretation have been recognised (e.g. Layder 1992), these data are arguably interdependent and relationally tied, and are thus considered here as a linguistic network composed of nodes that are linked by their perceived relationships. Such an approach allows the methodologies of social network analysis (hereinafter SNA) to be used for qualitative analysis purposes and has the potential to examine such a schema for evidence of centrality (relative importance) in order to develop a more coherent and structured narrative. SNA tools are based on graph theory, are interdisciplinary, and used in the scientific study of networks of many kinds encountered in a wide range of disciplines (e.g. Newman et al. 2006; Newman 2010; Wasserman and Faust 1994). One of the most useful methods used in SNA is to visualise linked data as a graph i.e. a network consisting of nodes (actors) joined by lines that represent ties that are either measured or observed, or interpreted as in the case of ideational data.

Table 8.2: Typology of ideational data.

\begin{tabular}{llll}
\hline Axis & Entrance & Memory & Sightline \\
Axis mundi & Experience & Place & Threshold \\
Boundary & Focal & Phenomenology & Transition \\
Edge & Genius loci & Processional space & Transitional space \\
Enclosure & Locus & Sacred space & Visual field \\
& & & Zoning \\
\hline
\end{tabular}


Using the data in Table 8.2, Figure 8.4 is the graph of all nodes and their proposed links. Each node is shown relatively scaled using the Degree Centrality $\left(\mathrm{C}_{\mathrm{D}}\right)$ index of centrality computed in UCINET 6 software (Borgatti and Everett 2002). The $C_{D}$ index ranks the relative importance of each actor in this network based on the number of ties/edges that connect it to other nodes. A standardisation of the measure is determined by:

$$
C_{D}^{\prime}\left(n_{i}\right)=\frac{d\left(n_{i}\right)}{g-1}
$$

where $\mathrm{g}=$ number of actors and $\mathrm{d}$ is a constant (Wasserman and Faust 1994, 179).

Notwithstanding the limitations and potentially subjective nature of the writer's approach as previously explained, the results show that based on the determined values of $\mathrm{C}_{\mathrm{D}}$, axis and processional space obtain the highest scores on such a scale $\left(\mathrm{C}_{\mathrm{D}}=8\right)$ and zoning the least $\left(C_{D}=2\right)$. These rankings are used to structure the following narrative.

\section{Axis, processional space (Degree Centrality 8)}

The majority of prehistoric constructs exhibit the concept of axis. It is the most basic planning device used to orientate and achieve symmetry in any built structure. In Ireland at least, megalithic monuments (tombs, circles and stone rows) show clear evidence of axiality and, in some cases, these probably symbolise culturally meaningful directions in terms of intentional alignment towards either built, landscape or celestial targets of symbolic importance. British Iron Age roundhouses similarly exhibit a strong sense of axiality as well as easterly orientation, some towards propitious celestial events at calendrically significant times (Cunliffe 2005, 577). Further comparisons can be made with European and British sites with reference to the spatial form of Iron Age ritual structures and the differential use of constructed space (Smith 2001; Webster 1995, 455-458). Significantly, Manley (2000) provides a highly relevant report on the likely method of design and use of Building 3 at the Fishbourne Roman Palace complex in England, which was constructed in the middle years of the 1st century AD. An Iron Age temple discovered at Heathrow further provides a tantalising glimpse of an enclosed settlement site in Britain that has exact chronological contemporaneity with Lismullin 1 (Grimes and Close-Brookes 1993). The roofed structure is a double-rectangle in plan with a formal portico entrance more typical of Early Roman temple architecture but on a much smaller scale than Lismullin 1. The timber post-holes are concentric and the co-aligned entrances face north-southeast (Fig. 8.5).

Grimes originally interpreted the rectangular structure as a temple when it was first discovered in 1944 but later interpretation by Close-Brooks advises caution on the use of this terminology, and of the possibility that it may have been a shrine (Grimes and CloseBrooks 1993, 331). In his study of the orientation of English churches, McCluskey (2007, 345) refers to the appropriateness of orientation in an easterly direction and has identified azimuth peaks centralised around east-northeast (similar to Lismullin 1). While this reference relates to a different tradition and set of dedications, a desire for orientation in that direction for religious/ritual reasons may be a common factor.

Axis, path (aisle) and centre are inextricably linked in a design sense. Taken together, axis and path convey a strong sense of directed physical movement toward or away from a focal target i.e. toward another element of the complex, or towards a target that may have cosmic significance in terms of how a building is used. Additionally, path is the 'fundamental existential symbol which concretises the dimension of time' (Norberg-Schulz 1980, 55). In 
the context of Lismullin 1, the avenue may have functioned as a 'via sacra' for the users, and until they reached the point where physical movement toward the sacred centre was impeded by the elongated pit containing burning charcoal. Such a concept has its design equivalent in modern Christian churches in terms of processional movement towards the terminus strategically located at the altar rails. This architectural element acts as a ceremonial barrier between public space and inner sacred space.

\section{Boundary, enclosure, focal, locus, place, threshold (Degree Centrality 7)}

The architectural completeness of temples conveys a measure of their sacredness and this usually denotes the concept of boundary acting to enclosure or exclude participants. Thus, the 'boundary or limit is a characteristic of sacred space' (Tuan and Strawn 2009, 21). Furthermore (ibid.), power and sacredness are intertwined there. Where a boundary is crossed or penetrated, as at the entrance to Lismullin 1 for example, the participant is moving between two worlds regulated by different operational codes and rites of behaviour. In an Iron Age context, Hingley $(1990,96)$ also refers to boundary as an element of enclosure, how it acts to socially exclude/include, and how it can perform as a symbol of status or power. Cunliffe $(2005,577)$ states that the interior spaces of Iron Age houses were probably carefully structured 'so as to contain behaviour', but that any evidence in support of that thesis was lacking. Additionally, he identifies structured space as a characteristic of all enclosed spaces and that these were governed by strict taboos and codes of practice conducted in specific designated spaces (and see Fitzpatrick 1997, 78). The English painter John White provides important sixteenth-century evidence of these concepts operating amongst the Secotan Indians of North Carolina (Fig. 8.6).

This depiction shows the Green Corn Festival which celebrated the first harvest of Indian corn (maize) at the end of summer. The elements of centre, enclosure, boundary and structured space are striking in this scene. The seven posts decorated with human faces are thought to symbolise deities. The sacred innermost space at the centre depicts three women and implies segregation between them and the encircling participants bearing gourds and branches.

The activities shown in Figure 8.6 additionally epitomise focality i.e. centrality of design that draws the eye and thus focuses the attention of participants in the ritual. As argued by Fleming $(1972,59)$ the minimum design requirement for ritual space must include focal point(s) for the activities of the principals. While locus may denote a focal point, it more explicitly describes a very specific place chosen for its genius loci properties in keeping with the intended role of the monument. The concept of place conveys the human desire to select a temple site that will embody the necessary/ideal topographical, elemental and other characters befitting its ritual function. These ideas are previously exemplified in Figure 8.1 by the landscape setting and the optimal scale and centralised positioning of the monument within the enclosing ridge.

The element of threshold is dramatically articulated at Lismullin 1 by the location of the elongated depositional pit - spatially and proportionally located between the western end of the avenue and the inner enclosure. The concept of threshold conveys the strongest sense of barrier and significance in design terms. Votive offerings are known to have been placed in the pit and such acts of ritual were possibly synchronised to take place in the period of the year following the annual harvest. Elsewhere, support for such an argument is found in an interpretative description of every day life in Iron Age Wessex (Fitzpatrick 1997, 80). 


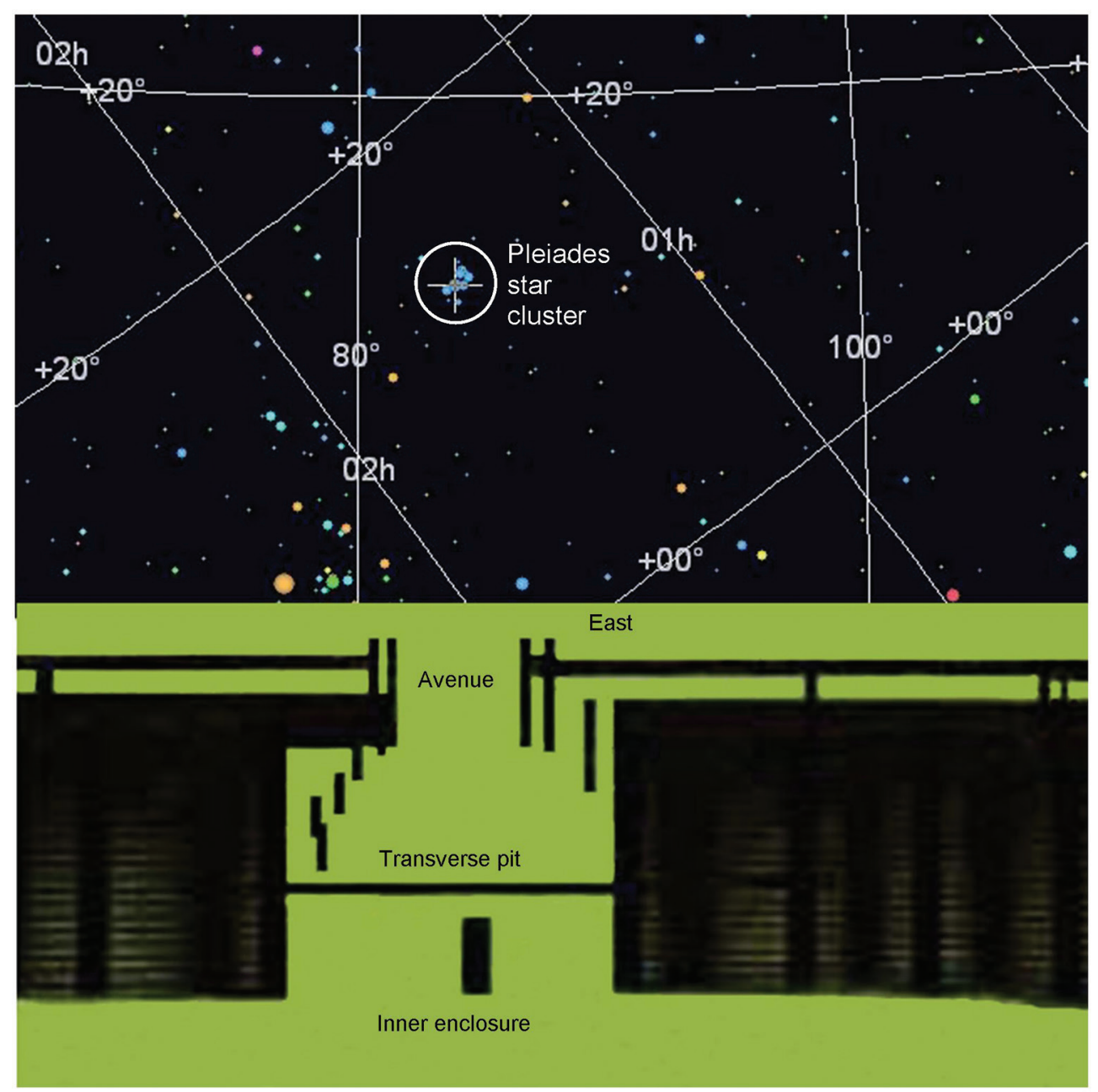

Fig. 8.3: Autumnal sky viewed from the inner enclosure in c. $400 \mathrm{BC}$.

Axis mundi, memory, sightline, transitional space (Degree Centrality 6)

Sacred architecture has, and always had, a 'mediating role' and 'the sacred place was (and still is) an intermediate zone created in the belief that it had the ability to engage, elucidate and transform' (Barrie 2012). In his discourse on religion and architecture, Barrie further argues that the root meaning of religion is to 'bind together', and that connection to a deeper understanding is only possible through belief and participation in religion so as to connect humans with their gods. Thus, the creation of ritual space, and place, is a human act intended to 'embody symbolic content' (ibid.) and to demarcate it for transformation and special use. The centre of such a space, once selected, assumes a new significance in terms of how it can figuratively link a built ceremonial structure to the cosmos in a vertical 


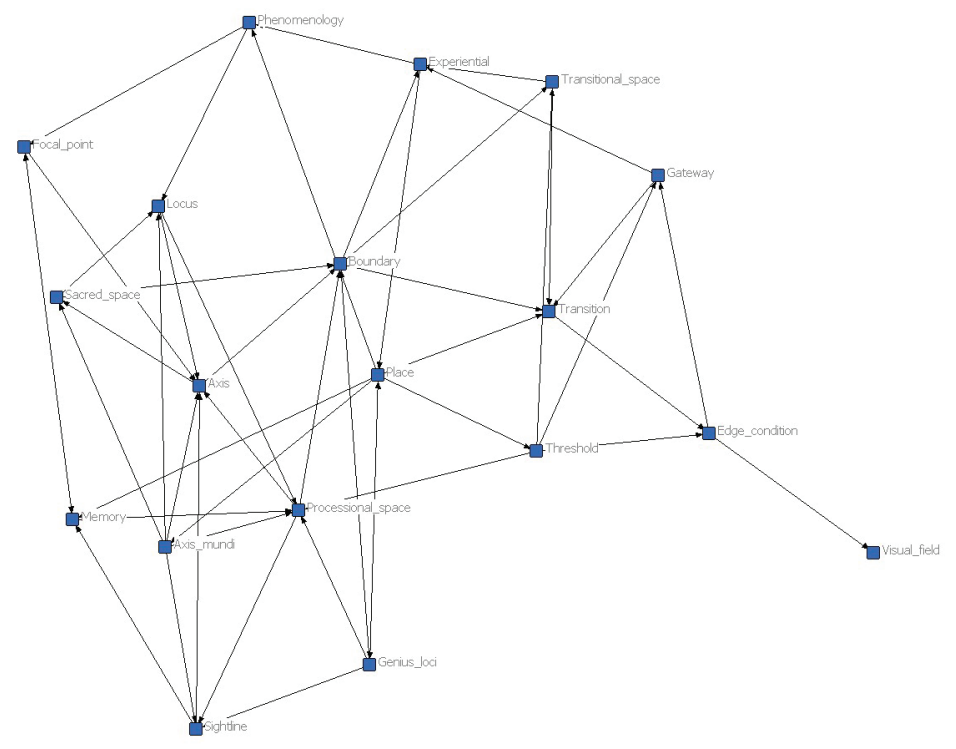

Fig. 8.4: Degree centrality scores.

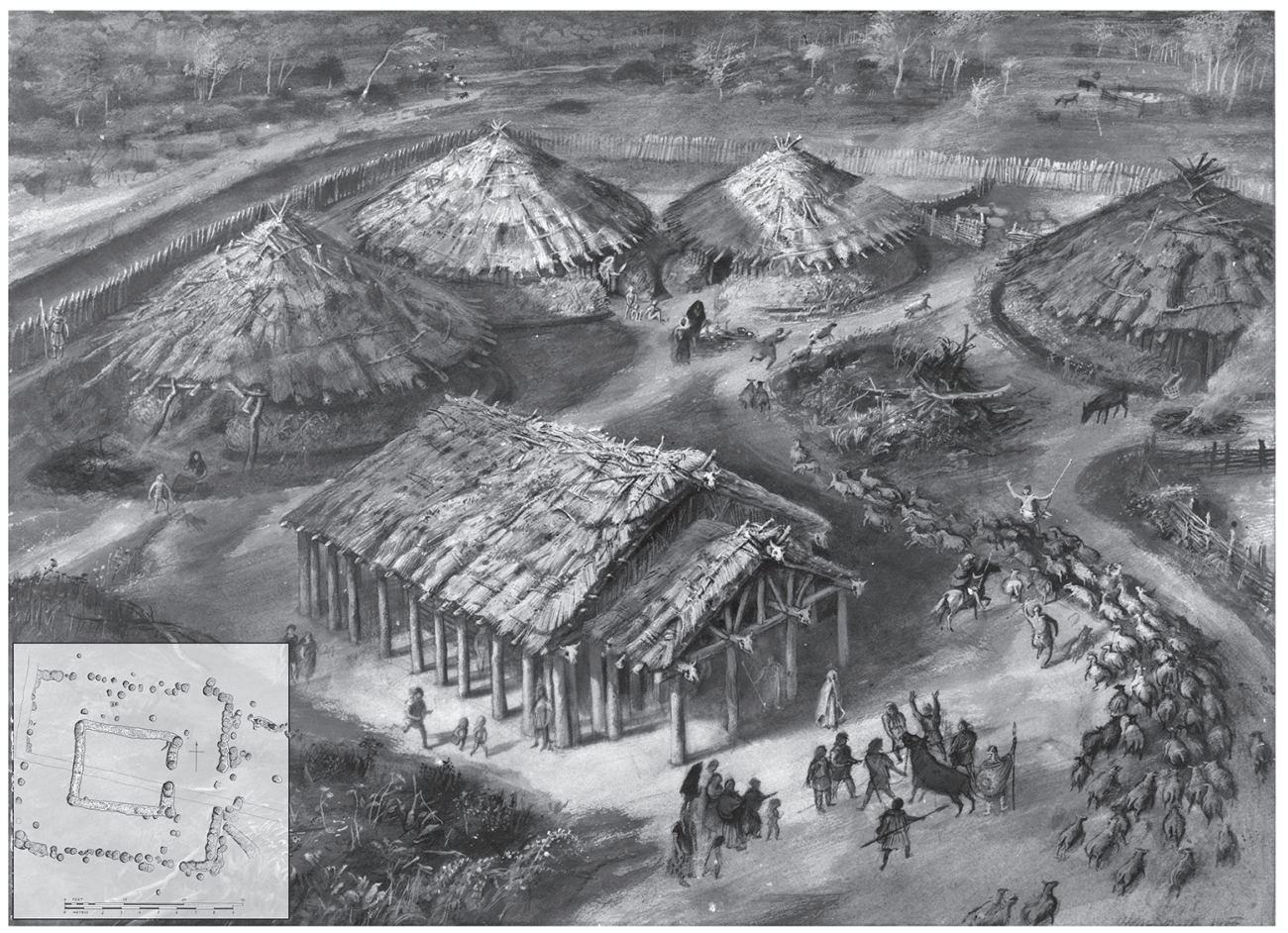

Fig. 8.5: Reconstruction of an Iron Age temple and farm at Heathrow in c. 500-300 BC by Alan Sorrell (C) Museum of London and Bridgeman Art Library. (Inset: archaeological plan of the temple after Grimes and Close-Brooks 1993, fig. 9). 
sense - either above (zenith) or below (nadir). This defines axis mundi (Fig. 8.9). Jaffé $(1999,272)$ provides support for this argument in relation to designed classical or primitive building foundations and how those could be "transformed into an ordered cosmos, a sacred place bound by its centre to the other world'.

The element of sightline is considered crucial in terms of the performance aspects of a building or a temple (Rykwert 1988). Sightline incorporates directionality and links the eye of the viewer/audience with a ritual referent - architectural, topographical or celestial. At Lismullin 1, the eye of the participant located within the inner enclosure would have been directed along the axis of the avenue towards the horizon and the sector of sky laterally bounded/framed by the avenue sides. As a design factor, Ritchie $(2004,11)$ links constructs and the horizon by stating 'skylines can themselves be monuments and monumental'.

In any ritual setting, formal movement is a core behavioural act. Thus, entering, exiting and processing within or around the complex through its designated spaces can help to realise the designer's ideas and ritual expectations of transitional space and as a zone of engagement to be used at auspicious times.

\section{Edge (Degree Centrality 5)}

Although equivalent in one sense, edge, unlike boundary, describes the experience and perception of being positioned at the periphery. At such a location, inclusion and exclusion become metaphors for social status and entitlement for participation in ritually controlled acts.

\section{Entrance, genius loci, sacred space, visual field (Degree Centrality 4)}

Krier $(1992,46)$ considers an entrance to be a symbol and as 'playing a decisive role in preparing the visitor for the spatial event to come' and for it to be 'in geometrical harmony' with the space within. At Lismullin 1, the emphasised nature of the larger-diameter post-holes suggests that the entrance (like a doorway) was intended to be proportionately in harmony with the large area enclosed by the $80 \mathrm{~m}$ diameter enclosure beyond. Such aspirations are described by Krier $(1992,27)$ as reflecting a desire to achieving 'a well balanced and meaningful composition that reflect an understanding of the relationship between form, proportion, effect and function'. An entrance is also another example of a threshold that can be used to divide, demarcate and segregate different designations of space and users (Fig. 8.8).

Genius loci refers to the idea of the character of a place or a landscape. It is experiential rather than quantifiable. Thus, at Lismullin 1, the elements contributing to its genius loci would have been the discreteness of its setting, the feeling of locally pronounced elevation above the river, proximity to the river, the act of ascension needed to access the complex, and visibility of the sky.

Sacredness implies reverence - either for a place, a structure or an object. Sacred space may contain a shrine or a temple. The shrine and the temple are manifestations of sacredness, each differing in their scale and context. In some cases, a shrine may be part of a larger temple. Both, however, embody a given set of religious beliefs and traditions.

When viewing Lismullin 1, its architecture has a strong bias in the horizontal plane; the relatively low height of the reconstructed timber posts and mostly level ground confirms this (Fig. 8.9; and see O' Connell 2013, 65). It might be argued, then, that the visual field and impact generated by the structure is in harmony with the dominant biological bias of the human eye in that plane. 
Experiential, phenomenology, transition (Degree Centrality 3)

Impact and feeling result from being situated in a particular space or ceremony and these qualities capture the essence of experience and phenomenology (e.g. Husserl 1970, 219-220; Tilley 1994, 11-17). The functioning of a temple involves movement and transition from space to space in a coordinated manner, and as dictated by ceremonial codes of behaviour.

\section{Zoning (Degree Centrality 2)}

Zoning is a conceptual planning tool that achieves its intended design aims through the regulated use of entrances, boundaries and pathways. Where successfully used, physical movement and mental transition can become unified in terms of the overall design rationale.

\section{Structured Space - Structuring Space}

Reconstructing prehistoric traditions is normally reliant on assessing the context of extant material culture recovered by archaeological excavation. Such approaches are sometimes constrained by how such evidence can be interpreted in a social context. Where applicable, the mechanism of oral tradition may only hint at this in some cases. The existence of any early literary sources that record traditions in a time chronologically close to a lost history is thus of immeasurable importance. Mac Cana $(1995,779)$, however, advises caution on the 'degree to which the extant corpus of medieval Irish literature may be accepted as a reliable index on native mythology and religion'. He emphasises the inherent dangers posed by reliance on early chroniclers whose writings are based on earlier descriptions of the beliefs and practices of continental and British Celts recorded by the various Greek classical authors (e.g. Diodorus, Hecateus, Hesiod). Mac Neill (1921-1924) has arguably overcome this problem through his translations of the chief collection of the oldest written Irish laws of jurisprudence. These are contained in a compilation called Senchus Már which can be dated to the seventh century AD. The collection was written at a time when Ireland was divided into c. 90 Tuathas (provinces) each ruled by a king. Chronologically, this knowledge was recorded just a few centuries after the ending of the Late Iron Age. It contains an important and relevant description of the 'law of status' as used by a king to segregate residential space and position guests in his house (ibid. 308). There is a clear reference to entrance orientation, and orientated seating arrangements of the guests according to their status, dignity and precedence (Fig. 8.7).

In the example, the entrance is positioned in the west and the seating of guests adheres to a strict protocol. Principals were seated in two rows aligned east-west and these faced each other (due north and south). The king, his wife and a judge sat in the east and thus faced west towards the entrance. While the evidence for this is literary only, such a schema (conceptually at least) is a likely metaphor for power and status attained through structured space.

\section{A typology of structured ritual space}

Architecture typologically classifies space through the recognition of ground plan shapes and groups these in terms of their function in a building or space. At Lismullin 1, the variation 


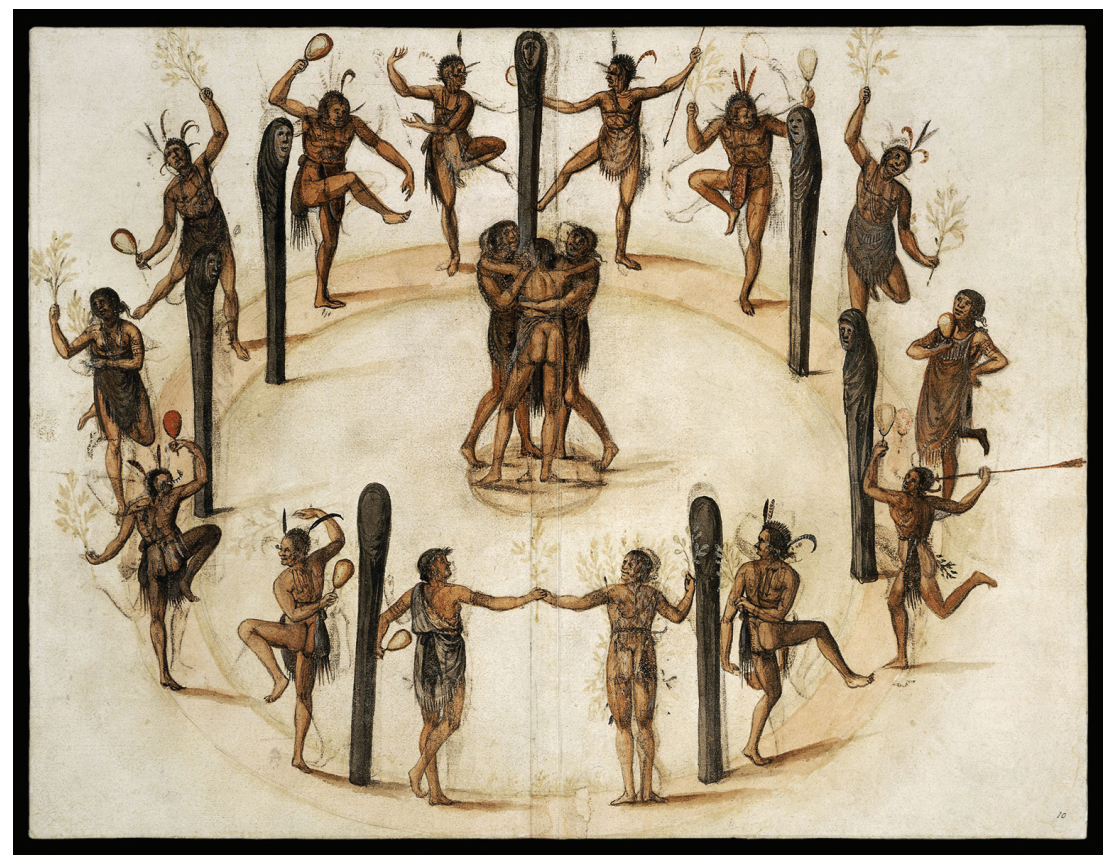

Fig. 8.6: Festive harvest dance of the Secotan Indians c. AD 1585-93 (C) The British Museum.

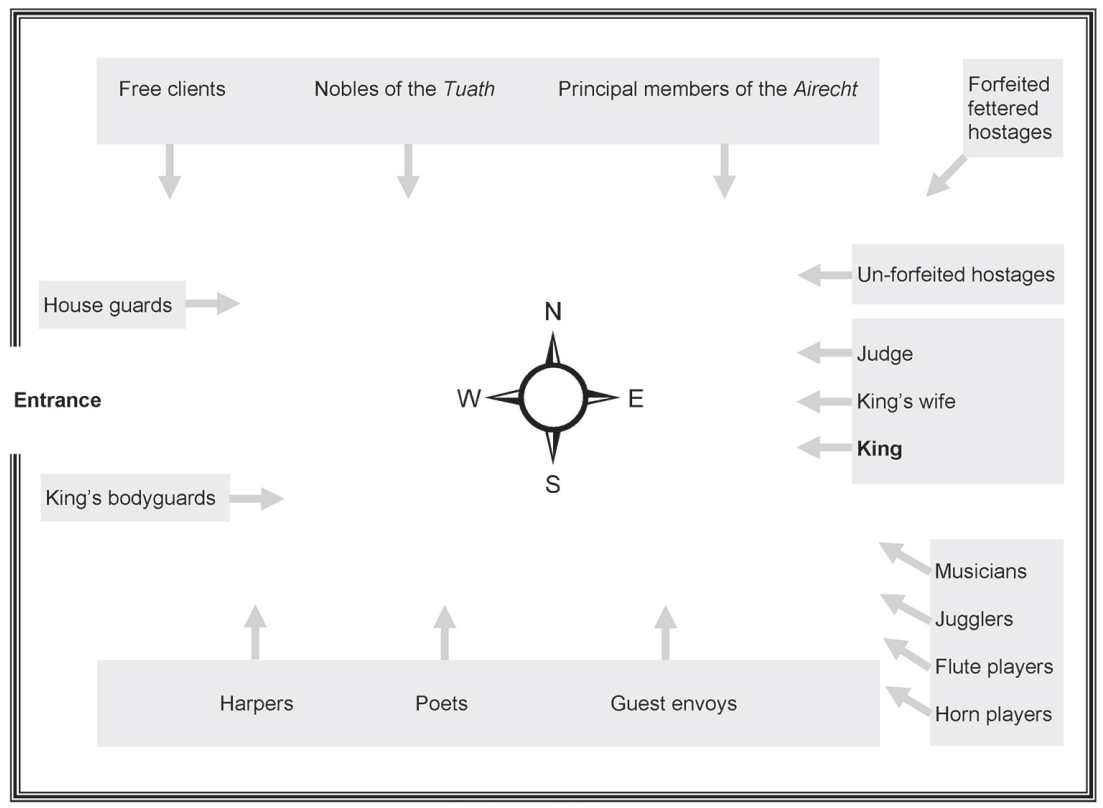

King's guards (4)

Fig. 8.7: The law of social status in 7th century Ireland (after Mac Neill 1921-24). 


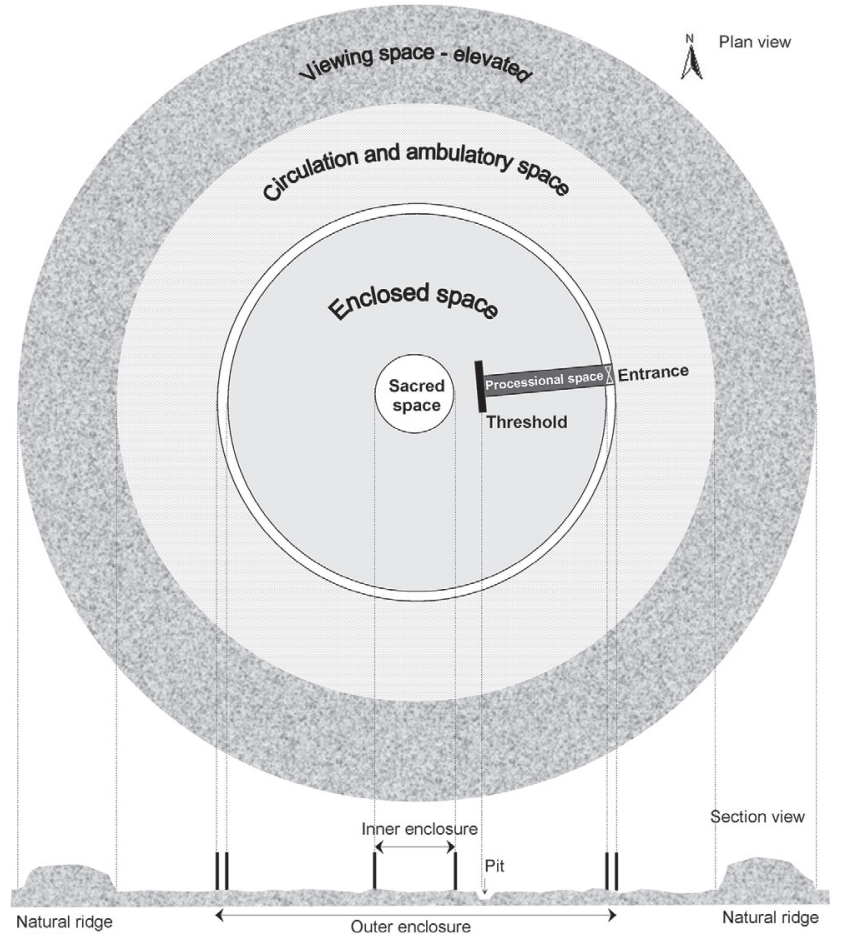

Fig. 8.8: Typology of structured space for Lismullin 1.

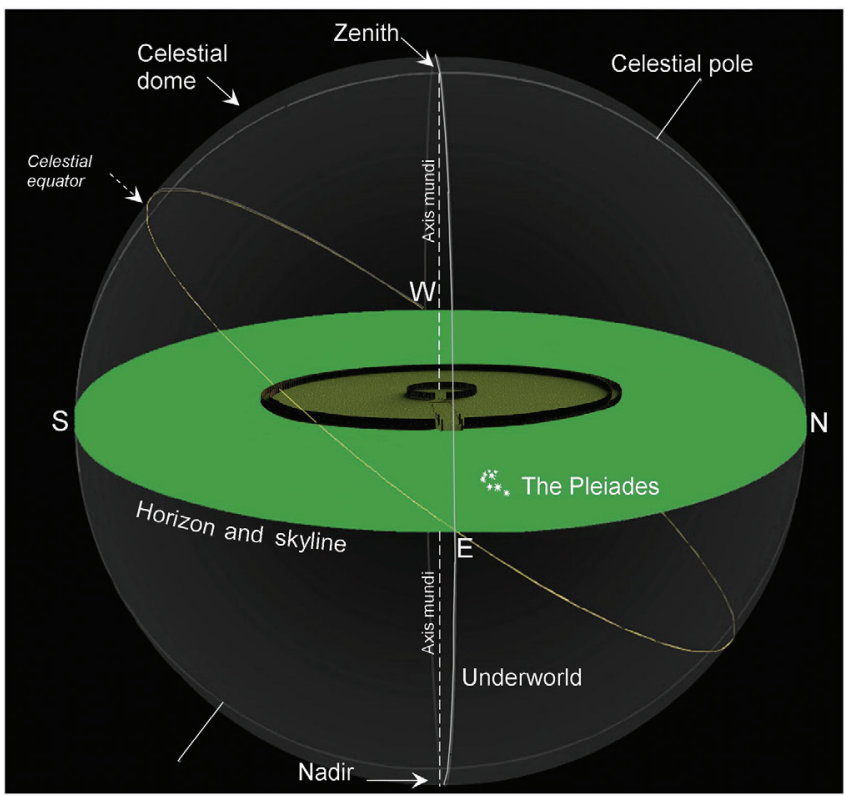

Fig. 8.9: A cosmology for Lismullin 1. 
in geometric form is simple and limited. Nonetheless, a typologically structured approach to viewing such a space suggests how setting, form and function can arguably achieve balance and harmony in the overall design (Fig. 8.8).

What may be significant is the manner in which the pit is geometrically offset from the central enclosure. Yet, it is strongly tied and balanced to the axiality of the complex, the avenue and the entrance. When viewed in this manner, the design and spatial relationships of the elements are more clearly understood in terms of their potential ritual role and function.

\section{Conclusion}

Cosmic order and harmony in any society can be achieved through the mechanism of architecturally motivated spatial organisation. Such concepts, and the elegant use of built form, are well articulated in classical Greek and Roman temple architecture. Those harbour many layers of embedded meaning beyond their known dedication to important deities. However, across space, time and cultures, the spontaneous appearance of similar archetypes, and ideas, does not necessarily depend on outside contact, or an invasion hypothesis, to explain their presence. Such manifestations can reproduce themselves anywhere in any time, and need not have had a known origin (Jung 1990, 58). Indeed, at the time Lismullin 1 was in use, Ireland largely existed beyond any influence from Roman Britain (Raftery 1995, 638-39). Raftery also claims that after about 600 BC, Ireland lapsed into a phase of 'introspective isolation', Hallstatt D influences to be almost undetectable, and the earliest phases of the continental La Tène culture to be entirely absent. It would not be until c. 300 $\mathrm{BC}$, when Lismullin 1 went out of use that any significant evidence of external links with Britain, or beyond, can be discerned in the record. That argument is consistent with the idea that a common religion or belief system did not exist in any wider regional sense (Joy 2011, 405) and that, instead, Iron Age religion was practised on a local scale.

Lismullin 1 exhibits the hallmarks of a temple site - large scale, formal entrance, processional space, threshold, depositional space, viewing space, openness and planned orientation. Interestingly, any evidence for prehistoric sacred space in Iron Age Ireland is scant. Thus Raftery $(1994,179)$ alludes to the difficulty of reconstructing religious beliefs from a minimal archaeological record and the need, instead, for tentative suggestions and questions. For Iron Age Britain, Smith $(2001,9)$ describes a similar dearth of evidence there, and that 'any great homogeneity of religious function' cannot be assumed.

In attempting to reconstruct a cosmology for Lismullin 1, wider concerns with how religion was practiced in the prehistoric are relevant though. As Ingold $(2007,154)$ states 'Certainly religion and its associated philosophies and rituals can be more pragmatic, and utilitarian, than our interpretations often allow, and involve the fusion of practical, economic, and esoteric concerns.' Based on the evidence and argument presented here, the recurring religious/ritual/ceremonial acts conducted at Lismullin 1 might be conceived as being part of the hypothetical world view model shown in Figure 8.9.

Here, the axis mundi anchors the centre of the temple to the apparent dome of the sky and creates a bipartite division of the world - above and below the horizon. Cardinal directions are shown to signify a probable awareness of these directions, but not necessarily with any degree of precision. The temple, the surrounding landscape and skyline, and the deliberate 
easterly alignment of the avenue towards, perhaps, a meaningful celestial referent, complete the model.

While these ideas are site specific, they do have a universal relevance in time and space. Lewis-Williams $(2005,65)$ describes a regional tiered cosmology for the precolumbian inhabitants of Mesoamerica with elements that overlap the model developed here. As Jaffé $(1990,272)$ puts it, transforming space into an ordered cosmos accords with 'the vital feelings and needs of religious man'. When Faust $(2001,149)$ observed that the orientation of Iron Age houses in Israel predominantly faced the east and avoided the west, he could offer no functional explanation for the phenomenon, and advised that 'the solution should be sought in another realm'. Perhaps the discourse here has provided some enlightenment on this question by offering added perspectives that may enrich and deepen our understanding of an enigmatic monument and a lost history.

\section{References}

Aldhouse-Green, M. J. (2010) Caesar's Druids: story of an ancient priesthood. New Haven and London: Yale University Press.

Atkinson, R. J. C. (1961) Neolithic Engineering. Antiquity 35, 292-99.

Atkinson, R. J. C. (1974) Neolithic Science and Technology. Philosophical Transactions of the Royal Society of London A276 (1257), 123-31.

Barrie, T. (2012) Sacred Space and the Mediating Roles of Architecture. European Review, 20 (1), 79-84.

Becker, K. (2009) Iron Age Ireland - finding an Invisible people. In: G. Cooney, K. B. J. Coles, M. Ryan and S. Sievers (eds) Relics of old decency: archaeological studies in later prehistory: festschrift for Barry Raftery. Dublin: Wordwell, 353-361.

Borgatti, S. P. and Everett, M. G. (2002) Ucinet 6 for Windows: Software for Social Network Analysis. Harvard: Analytic Technologies.

Boutsikas, E. and Ruggles, C. (2011) Temples, Stars, and Ritual Landscapes: The Potential for Archaeoastronomy in Ancient Greece. American Journal of Archaeology 115, 55-68.

Ceci, L. (1978) Watchers of the Pleiades: Ethnoastronomy among Native Cultivators in Northeastern North America. Ethnohistory 25 (4), 301-17.

Cunliffe, B. W. (2002) The extraordinary voyage of Pytheas the Greek. London: Penguin.

Cunliffe, B. W. (2005) Iron Age communities in Britain: an account of England, Scotland and Wales from the seventh century $B C$ until the Roman conquest. London: Routledge.

Darvill, T. C. (2002) The concise Oxford dictionary of archaeology. Oxford: Oxford University Press.

Faust, A. (2001) Doorway Orientation, Settlement Planning and Cosmology in Ancient Israel During Iron Age II. Oxford Journal of Archaeology 20 (2), 129-55.

Fitzpatrick, A. (1997) Everyday life in Iron Age Wessex. In: A. Gwilt and C. Haselgrove (eds) Reconstructing Iron Age Societies: new approaches to the British Iron Age. Oxford: Oxbow Books, 73-86.

Fleming, A. (1972) Vision and Design: Approaches to Ceremonial Monument Typology. Man 7 (1), $57-73$.

Gibson, A. (2005) Stonehenge and timber circles. Stroud: Tempus.

Grimes, W. F. and Close-Brooks, J. (1993) The Excavation of Caesar's Camp, Heathrow, Harmondsworth, Middlesex, 1944. Proceedings of the Prehistoric Society 59, 303-60.

Heidegger, M. and Hofstadter, A. (1971) Poetry, Language, Thought. New York: Harper \& Row.

Hingley, R. (1990) Boundaries surrounding Iron Age and Romano-British settlements. Scottish Archaeological Review 7, 96-103. 
Holl, S., Pallasmaa, J. and Pérez-Gómez, A. (1994) Questions of perception: phenomenology of architecture. Tokyo: a $+\mathrm{u}$ pub.

Husserl, E. and Carr, D. (1989) The crisis of European sciences and transcendental phenomenology: an introduction to phenomenological philosophy. Evanston: Northwestern University Press.

Ingold, T. (2007) 'Natural' or 'Human' Spaces? Tallensi Sacred Groves and Shrines and their Potential Implications for Aspects of Northern European Prehistory and Phenomenological Interpretation. Norwegian Archaeological Review 40 (2), 138-158.

Jaffé, A. (1990) Symbolism in the visual arts. In: C. G. Jung (ed) Man and his symbols. London: Arkana, 255-322.

Joy, J. (2011) The Iron Age. In: T. Insoll (ed) The Oxford Handbook of the Archaeology of Ritual and Religion. Oxford: Oxford University Press, 405-421.

Jung, C. G., ed (1990) Man and his symbols. London: Arkana.

Kirch, P. V. (2004) Temple Sites in Kahikinui, Maui, Hawaiian Islands: their orientations decoded. Antiquity 78 (299), 102-14.

Krier, R. (1992) Elements of architecture. London: Academy Editions.

Lancaster, S. (2008) Analysis of Soil Thin Sections from the Enclosure at at Lismullin 1, Co. Meath. Unpublished report to Archaeological Consultancy Services Ltd on behalf of Headland Archaeology [online], http://www.m3motorway.ie/Archaeology/Section2/Lismullin1/ file, 16728 ,en.pdf.

Layder, D. (1993) New strategies in social research: an introduction and guide. Cambridge: Polity Press.

Lismullin 1, Co. Meath. Unpublished report to Archaeological Consultancy Services Ltd on behalf of Headland Archaeology.

Lewis-Williams, J. D. and Pearce, D. G. (2005) Inside the Neolithic Mind: consciousness, cosmos and the realm of the gods. London: Thames \& Hudson.

MacCana, P. (1995) Mythology and the Oral Tradition Ireland. In: M. J. Green (ed) The Celtic World. London and New York: Routledge, 779-794.

MacNeill, E. (1921-1924) Ancient Irish Law. The Law of Status or Franchise. Proceedings of the Royal Irish Academy C 36, 265-316.

Manley, J. (2000) Measurement and metaphor: The Design and meaning of building 3 at Fishbourne Roman Palace. Sussex Archaeological Collections 138, 103-13.

Marshall, P. D., Cook, G. and Prior, C. (2013) Appendix 1: Bayesian analysis. In: A. O' Connell (ed) Harvesting the Gods: an excavation at Lismullin, Co. Meath. Dublin: National Roads Authority.

McCarthy, D. (2010) Digging, data and dissemination. Seanda 5, 41.

McCluskey, S. (2007) Calendrical Cycles, the Eight Day of the World, and the Orientation of English Churches. In: C. L. N. Ruggles and G. Urton (eds) Skywatching in the Ancient World: New Perspectives in Cultural Astronomy. Studies in Honor of Anthony F. Aveni. Boulder: University Press of Colorado, 331-353.

McLaughlin, M. and Conran, S. (2008) The emerging Iron Age of South Munster. Seanda 3, 51-53.

Newman, M. E. J., Barabási, A.-L. and Watts, D. J., eds (2006) The structure and dynamics of networks. Princeton and Oxford: Princeton University Press.

Newman, M. E. J. (2010) Networks: an introduction. Oxford: Oxford University Press.

Norberg-Schulz, C. (1980) Genius loci: towards a phenomenology of architecture. London: Academy Editions.

Norberg-Schulz, C. (1985) The concept of dwelling: on the way to figurative architecture. New York: Rizzoli.

Norberg-Schulz, C. (2000) Architecture: presence, language, place. London: Thames \& Hudson.

O' Connell, A. (2013) Harvesting the Stars: a pagan temple at Lismullin, Co. Meath Dublin: National Roads Authority.

Oldfather, C. H. (1935) The Loeb Classical Library: Diodorus of Sicily Book II. London: Heinemann.

Oldfather, C. H. (1939) The Loeb Classical Library: Diodorus of Sicily Book III. London: Heinemann. 
Prendergast, F. (2012) The Lismullin Enclosure: design beyond the obvious in the Iron Age. In: B. Kelly, N. Roycroft and M. Stanley (eds) Encounters Between Peoples. Dublin: National Roads Authority.

Prendergast, F. (2013) The Lismullin Enclosure - a designed ritual space. In: A. O' Connell (ed) Harvesting the stars: a pagan temple at Lismullin, Co. Meath. Dublin: National Roads Authority.

Raftery, B. (1994) Pagan Celtic Ireland: the enigma of the Irish Iron Age. London: Thames and Hudson.

Raftery, B. (1995) Ireland: A world without Romans. In: M. J. Aldhouse-Green (ed) The Celtic World. London and New York: Routledge.

Ritchie, I. (2004) The Spire. Herne Bay: Categorical Books.

Ruggles, C. N. (2005) Ancient astronomy: an encyclopedia of cosmologies and myth. Santa Barbara and Oxford: ABC Clio.

Rykwert, J. (1988) The idea of a town: the anthropology of urban form in Rome, Italy and the ancient world. London: MIT Press.

Smith, A. T. (2001) The differential use of constructed sacred space in southern Britain, from the Late Iron Age to the 4th century AD. Oxford: Archaeopress.

Taylor, K. (2008) At home and on the road: two Iron Age sites in County Tipperary. Seanda 3, 54-55.

Tilley, C. (1994) A phenomenology of landscape: places, paths, and monuments. Oxford and Providence: Berg Publishers.

Tuan, Y.-F. and Strawn, M. (2009) Religion: from place to placelessness. Chicago: Center for American Places at Columbia College Chicago.

Wasserman, S. and Faust, K. (1994) Social network analysis: methods and applications. Cambridge: Cambridge University Press.

Webster, J. (1995) Sanctuaries and sacred places. In: M. J. Aldhouse-Green (ed) The Celtic World. London and New York: Routledge, 445-464.

Wilde, O. (1891) Intentions: The decay of lying, Pen, Pencil and poison, The critic as artist, The truth of masks. New York: Dodd, Mead and Company. 